\title{
The mysteries of rapidly destructive arthrosis of the hip joint: a systemic literature review
}

\author{
Lintao $\mathrm{Hu}^{1,2}$, Xianzuo Zhang $^{2}$, Nikolaos Kourkoumelis ${ }^{3}$, Xifu Shang ${ }^{1,2}$ \\ ${ }^{1}$ Department of Orthopedics, Affiliated Provincial Hospital of Anhui Medical University, Hefei 230001, China; ${ }^{2}$ Department of Orthopedics, The \\ First Affiliated Hospital of USTC (University of Science and Technology of China), Hefei 230001, China; ${ }^{3}$ Department of Medical Physics, School \\ of Health Sciences, University of Ioannina, Ioannina, Greece \\ Contributions: (I) Conception and design: X Zhang; (II) Administrative support: X Shang; (III) Searching Strategy: L Hu, X Zhang; (IV) Collection \\ and assembly of data: L Hu, X Zhang; (V) Data analysis and interpretation: L Hu, N Kourkoumelis; (VI) Manuscript writing: All authors; (VII) Final \\ approval of manuscript: All authors. \\ Correspondence to: Dr. Xianzuo Zhang. Department of Orthopedics, The First Affiliated Hospital of University of Science and Technology of China, \\ 17\# Lujiang Road, Hefei 230001, China. Email: zhangxianzuo@foxmail.com; Dr. Xifu Shang. Department of Orthopedics, Affiliated Provincial \\ Hospital of Anhui Medical University, 17\# Lujiang Road, Hefei 230001, China. Email: xifushang@ahslyygjwk.com.
}

\begin{abstract}
Rapidly destructive arthrosis (RDA) is considered a rare and poorly diagnosed disease but is now seen more frequently in practice due to ageing populations. The most typical radiological features are flat femoral heads, absence of articular cartilage, subchondral bone destruction and signs of joint effusion. These features could be found on X-ray or magnetic resonance imaging (MRI). Surgeons should consider the presence of RDA when patients show rapid femoral head destruction. The purpose of this study is to review the distinct clinical features and successful treatments which may lead to the diagnosis and early handling of RDA. A comprehensive review of the literature was undertaken using Preferred Reporting Items for Systematic Reviews and Meta-Analyses (PRISMA) guidelines with no language restrictions. Overall 23 publications with 17 detailed cases of RDA met the inclusion criteria. We found that the only prevalent factors associated with RDA were: (I) age greater than 60 years; (II) female gender; (III) presence of underlying systemic diseases such as rheumatoid arthritis, diabetes mellitus or systemic lupus erythematosus. Further studies should be conducted to clarify the histopathology and define the diagnosis as well as the treatment.
\end{abstract}

Keywords: Rapidly destructive arthrosis (RDA); risk factor; total hip arthroplasty; osteoarthritis (OA); systemic review

Submitted Aug 16, 2019. Accepted for publication Feb 11, 2020.

doi: $10.21037 /$ apm.2020.03.17

View this article at: http://dx.doi.org/10.21037/apm.2020.03.17

\section{Introduction}

Rapidly destructive arthrosis (RDA) is an unusual, poorly diagnosed disease. It was firstly reported by Forestier in 1957 and a standardized definition was provided by Lequesne in 1970: $50 \%$ articular space narrowing in 1 year or femoral head destruction $>2 \mathrm{~mm}$ in 1 year (1). The disease diagnoses that are only based on radiographic findings can be inconclusive. In some cases, they are easily misdiagnosed as rheumatoid arthritis, neuroarthropathy, septic arthritis, osteonecrosis of the femoral head, seronegative arthritis or osteoarthritis (OA). But in fact, the clinical, laboratory and pathologic symptoms of RDA are not in accordance with these diseases. The purpose of this systematic review is to investigate the clinical and 
pathophysiology features to facilitate correct diagnosis and prompt appropriate treatment of RDA.

\section{Materials and methods}

A comprehensive review of literature was undertaken using Preferred Reporting Items for Systematic Reviews and Meta-Analyses (PRISMA) guidelines with no language restrictions. Searches were conducted using the following databases: PubMed, Embase, Cochrane Library, Springer, and the Google Scholar search tool. The following keywords were used: "rapidly destructive osteoarthritis", "rapidly destructive arthropathy", "rapidly destructive coxarthrosis", "rapidly destructive arthrosis", "rapidly destructive arthrosis of the hip", "rapidly progressive osteoarthritis", "Postel's osteoarthritis", "destructive osteoarthritis" and "rapid destructive coxopathy". Two researchers selected potentially relevant abstracts and obtained full copies of the articles. In addition, the references of the articles were reviewed.

\section{Criteria for eligibility}

The studies selected were original clinical articles that addressed RDA in elderly patients with no language restrictions. Cases with pigmented villonodular synovitis, pathological bone fractures and neuroarthropathy-i.e., Charcot joint-were excluded. Date limits were set from the inception of the journal to March 2018.

\section{Data extraction}

The following data were extracted from the eligible articles and case studies: type of study, age, gender, comorbidities, symptoms and signs, diagnostic modalities, treatment and outcome.

\section{Statistical analysis}

As the majority of the data collected were from case reports and case series, statistical analysis was not possible. Descriptive statistics were employed where suitable.

\section{Results}

\section{Literature search}

After omitting repetitions and studies which did not fulfil the selection criteria, 23 case reports or case-control studies were included in the analysis. All of these studies were retrospective. Fourteen were reported in Asia (2-15), six in Europe (16-21) and three in America (22-24). In total, 17 detailed patient cases were included (one article reported two cases, see Table 1). Seven case-control studies and case series including 164 patients were also studied (Table 2). We also reviewed additional relevant articles to facilitate the development of the discussion. The literature search flowchart could be found in Figure 1.

\section{Epidemiology}

\section{Age}

A total of 17 cases reported the age of patients. The mean age was 69.2 years (range, 37-81 years). There were 3 patients under 60 years $(17.6 \%)$ with a mean age of 50.3 years (range, 37-57 years), and 14 patients over 60 years (82.4\%) with a mean age of 73.3 years (range, 66-81 years). The seven cohort studies reported a total of 164 cases, with a mean age of 70.5 years.

\section{Gender}

All studies (181 cases) included 37 males (20.4\%) and 144 females $(79.6 \%)$

\section{Disease bilaterality}

Among all reported studies (181 cases), bilateral arthropathy was found in three cases (1.7\%). In the majority (178 cases), RDA occurs unilaterally.

\section{Diagnosis}

The most commonly accepted diagnosis criteria of RDA was joint space loss occurring at a rate greater than $2 \mathrm{~mm}$ per year or if more than $50 \%$ of joint space was lost in one year, reported by Lequesne in 1970. RDA was often misdiagnosed as another disease, including rheumatoid arthritis, neuroarthropathy, septic arthritis, osteonecrosis of the femoral head, seronegative arthritis and osteoarthritis.

\section{Radiological findings}

\section{$\mathrm{X}$-ray}

In all patients, the weight-bearing area of the femoral head was flat. The articular cartilage was absent and the subchondral bone was destroyed.

\section{Magnetic resonance imaging (MRI)}

All patients had hip joint effusion and evidence of synovitis. 
Table 1 Clinical characteristics of the 17 patients

\begin{tabular}{|c|c|c|c|c|c|c|c|c|c|c|c|c|}
\hline Author & Year & Age & Gender & $\mathrm{BMI}$ & $\begin{array}{l}\text { Affected } \\
\text { side }\end{array}$ & Comorbidities & Trauma & $\begin{array}{c}\text { Course of } \\
\text { disease }\end{array}$ & Blood test & $\begin{array}{l}\text { Bone marrow } \\
\text { edema }\end{array}$ & $\begin{array}{l}\text { Diagnostic } \\
\text { modalities }\end{array}$ & $\begin{array}{c}\text { Early } \\
\text { subchondral } \\
\text { fracture }\end{array}$ \\
\hline Yamamoto & 2010 & 57 & $\mathrm{~F}$ & 19.7 & Bilateral & Hyperlipidemia & No & $10 \mathrm{M}$ & Normal & - & X-ray & Yes \\
\hline Celik & 2015 & 78 & M & - & Bilateral & & - & $2 Y$ & $\begin{array}{c}\mathrm{ESR}=34 \\
\mathrm{~mm} / \mathrm{h}\end{array}$ & - & X-ray & Yes \\
\hline Laroche & 2002 & 67 & M & - & Left & $\begin{array}{c}\text { Coronary heart } \\
\text { disease } \\
\text { diabetes mellitus } \\
\text { occlusive arterial } \\
\text { disease }\end{array}$ & - & $3 \mathrm{M}$ & $\begin{array}{c}\mathrm{ESR}=25 \\
\mathrm{~mm} / \mathrm{h} ; \mathrm{CRP} \\
=10 \mathrm{mg} / \mathrm{L}\end{array}$ & $\begin{array}{l}\text { Subchondral } \\
\text { bone edema }\end{array}$ & X-ray + MRI & Yes \\
\hline Yun & 2012 & 67 & $\mathrm{~F}$ & 19.9 & Left & $\begin{array}{l}\text { Rheumatoid } \\
\text { arthritis }\end{array}$ & No & $6 \mathrm{M}$ & $\begin{array}{c}\mathrm{ESR}=23 \\
\mathrm{~mm} / \mathrm{h} ; \mathrm{CRP} \\
=79.5 \mathrm{mg} / \mathrm{L} ; \\
\mathrm{RF}=50 \mathrm{IU} / \\
\mathrm{mL}\end{array}$ & - & X-ray & - \\
\hline Yun & 2012 & 67 & M & 16.9 & Left & $\begin{array}{l}\text { Rheumatoid } \\
\text { arthritis }\end{array}$ & No & $6 \mathrm{M}$ & $\begin{array}{c}\mathrm{ESR}=75 \\
\mathrm{~mm} / \mathrm{h} ; \mathrm{CRP} \\
=418.5 \mathrm{mg} / \\
\mathrm{L} ; \mathrm{RAF}=47 \\
\mathrm{IU} / \mathrm{mL}\end{array}$ & $\begin{array}{l}\text { Severe cartilage } \\
\text { erosion }\end{array}$ & X-ray + MRI & - \\
\hline Fukui & 2015 & 77 & $\mathrm{~F}$ & 22.5 & Left & No & No & $5 \mathrm{M}$ & - & $\begin{array}{l}\text { Femoral head and } \\
\text { the acetabulum }\end{array}$ & X-ray + MRI & Yes \\
\hline Suzuki & 2018 & 80 & $\mathrm{~F}$ & - & Right & $\begin{array}{l}\text { Hypertension and } \\
\text { dyslipidemia }\end{array}$ & No & $3 \mathrm{M}$ & - & - & X-ray + CT & Yes \\
\hline Homma & 2014 & 80 & $\mathrm{~F}$ & - & Left & $\begin{array}{c}\text { Right } \\
\text { postoperative } \\
\text { THA }\end{array}$ & No & $2 M$ & 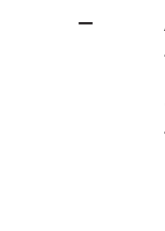 & $\begin{array}{l}\text { Acetabulum, } \\
\text { femoral head } \\
\text { and neck and } \\
\text { the irregular focal } \\
\text { high-intensity } \\
\text { bands }\end{array}$ & X-ray + MRI & - \\
\hline
\end{tabular}

Table 1 (continued) 
Table 1 (continued)

\begin{tabular}{|c|c|c|c|c|c|c|c|c|c|c|c|c|}
\hline Author & Year & Age & Gender & $\mathrm{BMI}^{\prime}$ & $\begin{array}{l}\text { Affected } \\
\text { side }\end{array}$ & Comorbidities & Trauma & $\begin{array}{l}\text { Course of } \\
\text { disease }\end{array}$ & Blood test & $\begin{array}{l}\text { Bone marrow } \\
\text { edema }\end{array}$ & $\begin{array}{l}\text { Diagnostic } \\
\text { modalities }\end{array}$ & $\begin{array}{c}\text { Early } \\
\text { subchondral } \\
\text { fracture }\end{array}$ \\
\hline Lee & 2015 & 37 & $\mathrm{~F}$ & 22.3 & Right & $\begin{array}{c}\text { Systemic lupus } \\
\text { erythematosus } \\
\text { (SLE) }\end{array}$ & No & 4-13 M & $\begin{array}{c}\text { WBC } \\
=4,000 / \\
\mu \mathrm{L}, \mathrm{PLT} \\
=180 \times 10^{3} / \\
\mu \mathrm{L}, \mathrm{C} 3=90 \\
\mathrm{mg} / \mathrm{dL}, \mathrm{C} 4 \\
=20 \mathrm{mg} / \mathrm{dL}\end{array}$ & $\begin{array}{l}\text { Femoral head and } \\
\text { the acetabulum }\end{array}$ & X-ray + MRI & Yes \\
\hline Marley & 2013 & 74 & $\mathrm{~F}$ & - & Left & Osteoarthritis & No & $9 \mathrm{M}$ & Normal & - & X-ray & - \\
\hline Hamada & 2014 & 69 & $\mathrm{~F}$ & - & Left & Ochronosis & No & - & $\begin{array}{c}\mathrm{CRP}=7.7 \quad \\
\mathrm{mg} / \mathrm{L}, \\
\mathrm{HLA}-\mathrm{B} 27(-)\end{array}$ & $\begin{array}{l}\text { Femoral head and } \\
\text { the acetabulum }\end{array}$ & X-ray + MRI & Yes \\
\hline Hama & 2015 & 70 & $\mathrm{~F}$ & - & Right & $\begin{array}{c}\text { Severe platelet } \\
\text { deficiency, liver } \\
\text { cirrhosis, immune } \\
\text { thrombocytopenic } \\
\text { purpura }\end{array}$ & No & $3 \mathrm{M}$ & $\begin{array}{c}\mathrm{CRP}=27.7 / \\
\mathrm{mg} / \mathrm{L}, \mathrm{RBC} \\
=243 \times 10^{4} / \\
\mu \mathrm{L}, \mathrm{PLT} \\
=2.2 \times 10^{4} / \mu \mathrm{L}\end{array}$ & & X-ray & - \\
\hline
\end{tabular}

(-), absence.

Diffuse signal abnormalities were found in the marrow of the femoral head and neck. None of the patients exhibited chondrocalcinosis (pelvis, knees), osteoarthritis radiographically or histopathologically. Low signal intensity occupied the whole femoral head on T1-weighted images. The same area showed high signal intensity on T2weighted images. A small low-intensity line was observed at the weight-bearing area (25).

\section{Potential risk factors}

\section{Body mass index (BMI)}

Seven cases reported the BMI of the patients. Six patients had the standard BMI (range, 19.7-22.8) and one had a lower BMI (16.9).

\section{Trauma}

None of the cases reviewed showed evidence of trauma at the onset of disease.

\section{Corticosteroid and alcohol}

Only four patients had a history of glucocorticoid administration and two patients reported daily consumption of alcohol. One of them had both corticosteroid and alcoholism.

\section{Secondary contralateral hip osteoarthritis}

There was insufficient evidence to suggest that patients with 


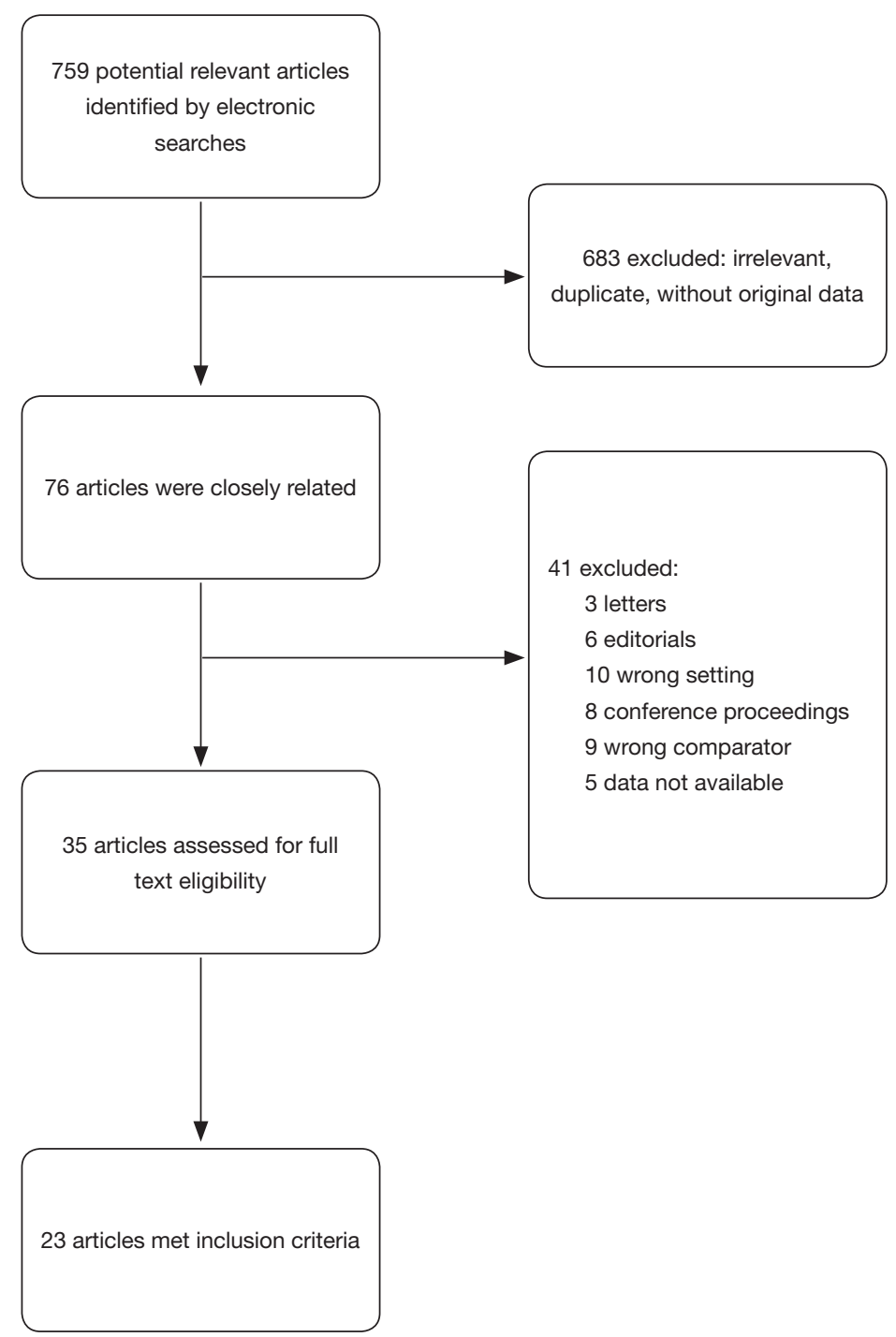

Figure 1 Flow diagram of scientific literature search and study selection.

RDA have a higher risk of developing osteoarthritis in the contralateral hip than patients with OA (26).

\section{Bone mineral density (BMD)}

One study reported that no significant differences were observed in BMD between RDA and OA patients (27).

\section{Clinical characteristics}

\section{Symptoms and signs}

A total of 17 cases included the pain and limitations reported by patients suffering from RDA. Because of the intractable severity of pain, two patients underwent a total hip replacement $(2,9)$. Twelve patients were reported to have 38.3 \pm 3.07 (range, 33-42) points in the Harris Hip Score (15). Two patients were unable to walk because of the pain $(8,11)$. One case reported the pain level as $9 / 10$ by visual analog scale and their Barthel Index was 25 suggesting extreme dependence for others when carrying out daily activities.

\section{Comorbidities}

The cases reported hyperlipidemia, tonsillectomy, coronary heart disease, diabetes mellitus, occlusive arterial disease, rheumatoid arthritis, hypertension, systemic lupus erythematosus, ochronosis, severe platelet deficiency, 
Table 2 Summary of findings in the case series and cohort studies of RDA

\begin{tabular}{|c|c|c|c|c|c|c|c|}
\hline Author & Year & Country & Sample size & Side & Gender & Control & Summary of findings \\
\hline Charrois & 2001 & France & 100 & - & $86 \mathrm{~F} / 14 \mathrm{M}$ & $100(53 \mathrm{~F} / 47 \mathrm{M})$ & $\begin{array}{l}\text { The blood loss after THA performed for RDA } \\
\text { is greater than for regular coxarthrosis }\end{array}$ \\
\hline Yamakawa & 2005 & Japan & 6 & - & - & 6 & $\begin{array}{l}\text { Hypervascularity of the granulation in the } \\
\text { femoral head may be associated with bone } \\
\text { and joint destruction }\end{array}$ \\
\hline Ogawa & 2007 & Japan & 10 & - & $10 \mathrm{~F}$ & $40 \mathrm{~F}$ & $\begin{array}{l}\text { The underlying mechanism of RDA is therefore } \\
\text { associated with osteoclastogenesis in the } \\
\text { synovium }\end{array}$ \\
\hline Yuasa & 2016 & Japan & 12 & - & $12 \mathrm{~F}$ & $12 \mathrm{~F}$ & $\begin{array}{l}\text { Cemented or cementless THA achieved a } \\
\text { good midterm outcome. }\end{array}$ \\
\hline
\end{tabular}

liver cirrhosis, immune thrombocytopenic purpura, and esophageal varices as comorbidities of RDA.

\section{Medications}

Two patients used hydroxychloroquine and methotrexate for rheumatoid arthritis. One used thrombopoietin receptor agonist and Kenketsu Glovenin-I for immune thrombocytopenic purpura (9).

\section{Blood tests}

Nine cases reported normal blood tests in patients while seven cases reported higher than average erythrocyte sedimentation rate (ESR) and C-reactive protein (CRP).

\section{Pathophysiology}

\section{Subchondral fracture and bone marrow edema}

Of the cases with reported or clear radiographs, the subchondral fracture could be seen in 11 cases. There were nine cases reporting bone marrow edema in the acetabulum, femoral head and neck, or the irregular focal high-intensity bands.

\section{Osteoclasts infiltration}

Mature and activated osteoclasts were present in the synovium of RDA patients. Tartrate resistant acid phosphatase (TRAP) positive multinuclear giant cells present in synovial membrane showed the nature of osteoclasts $(12,13)$.

\section{Experience in treatment}

Most patients were treated with nonsteroidal antiinflammatory drugs (NSAIDs) and some patients were treated with alendronate sodium hydrate and alfacalcidol. They all reported negligible effects on the advance of the disease. Fifteen patients received total hip arthroplasty with no complications reported. Two other patients refused to have surgical treatment. The cohort studies also reported total hip arthroplasties (THAs) in 164 patients. The mean interval of time from hip pain onset to the surgery, reported in 16 cases, was 26.5 weeks, with a range between 6 and 54 weeks. The total blood loss was significantly greater in arthroplasty performed for RDA than patients with osteoarthritis. Sex, age and extra body weight index (BMI) had no significant effect on bleeding (14-16). The mean Harris Hip Score improved significantly after surgery (15). THA achieved a good midterm outcome comparable to that for patients with primary or secondary osteoarthritis $(15,28)$. Complications of the surgery were not different 
from complications suffered by osteoarthritis patients.

\section{Other findings}

The number of TRAP-positive multinuclear giant cells present in the synovial membrane obtained from RDA patients was significantly larger than that obtained from OA patients (13). The osteoclast count on the bone surface from the RDA patients was greater than that from the osteoarthritic patients (12).

\section{Discussion}

RDA is an unusual, poorly diagnosed disease whose pathophysiology and etiology are still unknown. Various aspects of RDA continue to attract a lot of attention from both researchers and clinicians. In this literature review, we searched potentially relevant articles in the databases and reviewed the references of the articles. We then summarized the epidemiology and clinical characteristics of RDA from all the cases reported so far, and investigated the potential risk factors, diagnostic modalities, and experience in treatment. Accordingly, this article aims to provide evidence for improving the diagnosis and treatment of RDA.

Several potential risk factors have been proposed in the literature, including: (I) ageing; (II) female gender; (III) underlying health problems such as rheumatoid arthritis, diabetes mellitus and systemic lupus erythematosus; (IV) lower bone mineral density; (V) higher BMI; (VI) medicinal drug use including NSAIDs and corticosteroid; (VII) alcoholism (2-17,19-24,27,29). In this study, we evaluated the risk factors and found the only prevalent factors were: (I) age greater than 60 years; (II) female gender; (III) underlying systemic disease such as rheumatoid arthritis, diabetes mellitus or systemic lupus erythematosus (2-17,19-21,23,24). There is insufficient evidence to support the relationship between $\mathrm{BMD}, \mathrm{BMI}$, medication and alcoholism and the occurrence of RDA $(2,3,5,8,10,23,27,29)$. We did not find these factors to increase the risk of RDA.

Most patients consulted a physician because of hip pain that had appeared without previous trauma or falls, and most of the disease progression occurred within one year. As a result, these changes were described as "rapid" and "destructive" in literature. Many of the patients were able to walk during their initial medical consultations, which may lead to the doctor failing to make an accurate diagnosis. Some studies mentioned that RDA was caused by simultaneous bilateral shoulder joint collapse within a very short time, with minimal or low mechanical stress and severe osteoporosis (30). Although disease diagnosis is possible through physical examination and medical history, the first symptoms of RDA are neither specific to the disease nor clear. We suggest that any patient who has the above-mentioned high-risk factors should suggest the possibility of RDA to their medical practitioner and that further diagnostic measures should be taken.

Blood tests, including CRP and ESR, are nonspecific in this disease. We recommend an X-ray of the hip as the initial radiological examination; doctors were able to make an RDA diagnosis in all of the reported cases that had X-rays. In all patients, the $\mathrm{X}$-rays showed that the weight-bearing area of the femoral head was flattened. Joint space loss at a rate greater than $2 \mathrm{~mm}$ per year, or if more than $50 \%$ of joint space had been lost in 1 year, were considered as RDA $(1,31,32)$. MRI was also used in many cases and significant changes were found. It was reported that a unique presentation of severe bone destruction as a manifestation of chronic myeloid leukemia in the absence of blast crisis (33). There were bone marrow edema on acetabulum, femoral head and neck and the weight-bearing area and the articular cartilage was absent with the subchondral insufficiency fracture or subchondral bone destroyed (2,3,5-8,10,34,35).

Physicians should be aware of antidiastoles when making a diagnosis of RDA. Gorham-Stout Syndrome (Gorham's massive osteolysis) and RDA of the hip show similarities in the idiopathic rapid disappearance of bones. However, histological examinations have revealed that Gorham's massive osteolysis is associated with angiomatosis of blood vessels and sometimes with lymphatics (12). Charcot's joint (neuropathic osteoarthropathy) and RDA have similarities in the slight clinical signs with serious imaging manifestation. Diabetes mellitus is the leading cause of neuropathic osteoarthropathy, with additional associations including syringomyelia, meningomyelocele and multiple sclerosis (36). It is easy to mistake RDA symptoms for symptoms of rheumatoid arthritis, septic arthritis, osteonecrosis of the femoral head, seronegative arthritis or osteoarthritis. The diagnosis of RDA should be exclusive.

We recommend direct joint replacement when the diagnosis is confirmed. Although cases with delayed replacement surgery showed no signs of malignancy or contralateral involvement (26), these patients showed negligible results on conservative treatment. Although Low-dose aspirin and monoclonal antibody against human receptor activator of nuclear factor- $\kappa$ B ligand (RANKL) were benefit for maintaining bone mass and qualities by 
activation of osteoblastic bone formation and inhibition of osteoclast activities via cyclooxygenase-independent manner $(37,38)$, the use of drugs such as NSAIDs, alendronate sodium hydrate and alfacalcidol had only mild or even no effect on the patients with RDA $(3,5,6,20,24,39,40)$. Total hip replacement is probably the treatment of choice for these patients. In $100 \mathrm{RDA}$ patients treated with cemented THA and followed up for a mean of 7.83 years, the Merle $\mathrm{d}$ 'Aubigne score was excellent or very good in 95 hips (41). Yuasa et al. reported that after an average follow-up duration of 9.3 years, the mean Harris Hip Score improved from 38.3 to 81.1 in RDA patients and from 43.6 to 84.2 in conventional osteoarthritis controls (15). During surgery, the total blood loss of patients with hip osteoarthritis was significantly less than patients with RDA $(9,14,16,35)$. Sex, age and extra body weight (BMI) had no significant effect on bleeding (14-16). The present study cannot explain the hemorrhagic nature of THA performed for RDA. We suppose that the excessive bleeding may be a result of the tissue edema or bone surface bleeding due to subchondral fractures. Operative time and the complexity of reconstructive efforts could be significantly reduced if the correct diagnosis was made early and surgical procedure was taken in time (32). Most RDA patients had the disease in a single joint and a few patients were reported as having bilateral RDA $(21,23)$. Patients with RDA may not have a higher risk of developing osteoarthritis in the contralateral hip after THA, than patients with osteoarthritis (26). But chronic lameness could lead to spinal diseases such as lumbar scoliosis. Although outcomes in the reviewed cases appeared to be satisfactory, this cannot be confirmed because of the small number of cases with follow-up.

Bone is in a dynamic process of continuous remodeling which helps to regulate calcium homeostasis, repair microdamage to bones from everyday stress, and to shape the skeleton during growth (42). Although the rapid clinical course and bone destruction in patients with RDA differ from those generally seen with a degenerative process, previously published reports have suggested that this disease is degenerative in nature and is a form or subset of OA $(12,13,38)$. The reason why some joints undergo rapid and progressive destruction remains unclear. If fragility is the only cause of subchondral fracture in RDA, then fractures might occur at the femoral neck rather than at the head beneath the cartilage (43). Many paracrine or autocrine factors that stimulate osteoclastic differentiation and function in the active area have been studied $(44,45)$. In patients with progressively destructive arthropathy, it has been reported that osteoclasts with vascular-rich granulation could be detected $(12,38,46)$. The osteoclast count was significantly greater in rapidly destructive arthropathic patients than in osteoarthritic patients $(12,38)$ and an increase in osteoclasts was found in the active areas of the hip in patients with RDA $(12,47)$. Several reports have shown that the elevated levels of bone-resorptive enzymes, such as interleukin-6 (IL-6), IL-1 $\beta$, and matrix metalloproteinases, were associated with RDA of the hip (12). Hypervascularity was also found to be an important factor associated with the destruction of the bone and joint in RDA patients. Endothelium could play an important role in the recruitment of osteoclast precursors to sites of bone resorption because osteoclast precursors could adhere to the endothelium and be activated with the IL- 6 secreted by endothelial cells $(12,13,46)$.

The strengths of this study include a comprehensive search and analysis of world literature with no year or language limitations, and the relatively complete information provided in the reviewed cases. The main limitation is the small number of cases previously reported. Further studies on this disease might improve our knowledge of the management of RDA.

\section{Acknowledgments}

We thank Kerong Wu, Zhe Ni, Min Chen and Zhengliang Luo for their assistants and professional opinions.

Funding: None.

\section{Footnote}

Conflicts of Interest: All authors have completed the ICMJE uniform disclosure form (available at http://dx.doi. org/10.21037/apm.2020.03.17). The authors have no conflicts of interest to declare.

Ethical Statement: The authors are accountable for all aspects of the work in ensuring that questions related to the accuracy or integrity of any part of the work are appropriately investigated and resolved.

Open Access Statement: This is an Open Access article distributed in accordance with the Creative Commons Attribution-NonCommercial-NoDerivs 4.0 International License (CC BY-NC-ND 4.0), which permits the noncommercial replication and distribution of the article with the strict proviso that no changes or edits are made and the 
original work is properly cited (including links to both the formal publication through the relevant DOI and the license). See: https://creativecommons.org/licenses/by-nc-nd/4.0/.

\section{References}

1. Lequesne M. Les coxopathies rapidement destructices inattendues. La Presse Med 1970;78:425-6.

2. Nishida K, Yamamoto T, Motomura G, et al. Early MRI findings of the acetabulum and femoral head in a dysplastic hip resulting in a rapid destruction of the hip joint. Arch Orthop Trauma Surg 2005;125:567-70.

3. Watarai K, Taneda H, Higano M, et al. Rapidly destructive arthrosis of the hip joint after insufficiency fracture of the acetabulum. J Orthop Sci 2008;13:561-5.

4. Yang JH, Oh KJ, Pandher DS. Hydroxyapatite crystal deposition causing rapidly destructive arthropathy of the hip joint. Indian J Orthop 2011;45:569-72.

5. Yun HH, Song SY, Park SB, et al. Rapidly destructive arthropathy of the hip joint in patients with rheumatoid arthritis. Orthopedics 2012;35:e958-62.

6. Hamada T, Yamamoto T, Shida J, et al. Subchondral insufficiency fracture of the femoral head in a patient with alkaptonuria. Skeletal Radiol 2014;43:827-30.

7. Homma Y, Baba T, Sumiyoshi N, et al. Rapid hip osteoarthritis development in a patient with anterior acetabular cyst with sagittal alignment change. Case Rep Orthop 2014;2014:523426.

8. Fukui K, Kaneuji A, Fukushima M, et al. Early MRI and intraoperative findings in rapidly destructive osteoarthritis of the hip: A case report. Int J Surg Case Rep 2015;8C:13-7.

9. Hama S, Inori F, Momose D, et al. Total Hip Arthroplasty for Rapidly Destructive Coxarthrosis in a Patient with Severe Platelet Deficiency due to Liver Cirrhosis and Immune Thrombocytopenic Purpura. Case Rep Orthop 2015;2015:469879.

10. Lee Y, Motomura G, Yamamoto T, et al. Rapidly destructive arthrosis of the hip joint in a young adult with systemic lupus erythematosus. Rheumatol Int 2015;35:1753-7.

11. Suzuki M. Rapid Destructive Coxopathy. Intern Med 2018;57:1807-8.

12. Yamakawa T, Sudo A, Tanaka M, et al. Microvascular density of rapidly destructive arthropathy of the hip joint. J Orthop Surg (Hong Kong) 2005;13:40-5.

13. Ogawa K, Mawatari M, Komine M, et al. Mature and activated osteoclasts exist in the synovium of rapidly destructive coxarthrosis. J Bone Miner Metab 2007;25:354-60.

14. Song JH, Han SK, Lee KH, et al. Comparison of Perioperative Blood Loss in Primary Non-cemented Total Hip Arthroplasty for Rapidly Destructive Coxarthrosis and Osteonecrosis of the Femoral Head. Hip Pelvis 2015;27:141-5.

15. Yuasa T, Maezawa K, Nozawa M, et al. Midterm outcome of total hip arthroplasty for rapidly destructive coxarthrosis. J Orthop Surg (Hong Kong) 2016;24:27-30.

16. Charrois O, Kahwaji A, Vastel L, et al. Blood loss in total hip arthroplasty for rapidly destructive coxarthrosis. International Orthopaedics 2001;25:22-4.

17. Boutry N, Paul C, Leroy X, et al. Rapidly destructive osteoarthritis of the hip: MR imaging findings. AJR Am J Roentgenol 2002;179:657-63.

18. Laroche M, Moineuse C, Durrou R. Can ischemic hip disease cause rapidly destructive hip osteoarthritis? A case report. Joint Bone Spine 2002;69:76-80.

19. Marley WD, Ruiz A. Rapidly progressive osteoarthritis presenting as acute limb shortening. BMJ Case Rep 2013. doi: 10.1136/bcr-2013-009086.

20. Shu J, Ross I, Wehrli B, et al. Rapidly destructive inflammatory arthritis of the hip. Case Rep Rheumatol 2014;2014:160252.

21. Celik C, Yalbuzdag SA, Erol A. Bilateral rapidly destructive hip osteoarthritis: a case report. Acta Reumatol Port 2015;40:291-3.

22. Yamamoto $T$. The role of subchondral insufficiency fracture in rapid destruction of the hip joint: a preliminary report. Arthritis Rheum 2000;43:2423-7.

23. Yamamoto T, Schneider R, Iwamoto Y, et al. Bilateral rapidly destructive arthrosis of the hip joint resulting from subchondral fracture with superimposed secondary osteonecrosis. Skeletal Radiol 2010;39:189-92.

24. Huerfano E, Bautista M, Bonilla G, et al. A case of rapidly destructive osteoarthritis of the hip with onset of less than six weeks. J Clin Orthop Trauma 2017;8:S72-S75.

25. Watanabe W, Itoi E, Yamada S. Early MRI findings of rapidly destructive coxarthrosis. Skeletal Radiol 2002;31:35-8.

26. Motomura G, Yamamoto T, Nakashima Y, et al. Outcome of the contralateral hip in rapidly destructive arthrosis after total hip arthroplasty: a preliminary report. J Arthroplasty 2006;21:1026-31.

27. Okano K, Aoyagi K, Enomoto H, et al. Bone mineral density in patients with destructive arthrosis of the hip joint. J Bone Miner Metab 2014;32:312-6. 
28. Kuo A, Ezzet KA, Patil S, et al. Total hip arthroplasty in rapidly destructive osteoarthritis of the hip: a case series. HSS J 2009;5:117-9.

29. Richette P, Vicaut E, De Vernejoul MC, et al. Bone mineral density in patients with rapidly destructive or common hip osteoarthritis. Clin Exp Rheumatol 2009;27:337-9.

30. Kakutani R, Kondo N, Mochizuki T. Rapidly Destructive Arthrosis of Bilateral Humeral Heads Caused by Subchondral Insufciency Fracture. Acta Med. Okayama 2018;72:525-30.

31. Rosenberg ZS, Shankman S, German C, et al. Rapid destructive osteoarthritis clinical, radiographic, and pathologic features. Radiology 1992;182:213-6.

32. Flemming DJ, Gustas-French CN. Rapidly Progressive Osteoarthritis: a Review of the Clinical and Radiologic Presentation. Curr Rheumatol Rep 2017;19:42.

33. Howard J, Mackenzie B, Nicholson T, et al. A unique presentation of destructive shoulder arthropathy in the chronic phase of chronic myeloid leukaemia. Shoulder Elbow 2019;11:210-4.

34. Viana SL, Machado BB, Mendlovitz PS. MRI of subchondral fractures: a review. Skeletal Radiol 2014;43:1515-27.

35. Kubo Y, Motomura G, Ikemura S, et al. Osteoclastrelated markers in the hip joint fluid with subchondral insufficiency fracture of the femoral head. J Orthop Res 2018;36:2987-95.

36. Porrino J, Carlson B, Kani KK, et al. Disappearing Acts: The Many Causes of Rapidly Destructive Arthritis. Curr Probl Diagn Radiol 2017;46:63-73.

37. Xie Y, Pan M, Gao Y, et al. Dose-dependent roles of

Cite this article as: Hu L, Zhang X, Kourkoumelis N, Shang X. The mysteries of rapidly destructive arthrosis of the hip joint: a systemic literature review. Ann Palliat Med 2020;9(3):1220-1229. doi: 10.21037/apm.2020.03.17 aspirin and other non-steroidal anti-inflammatory drugs in abnormal bone remodeling and skeletal regeneration. Cell Biosci 2019;9:103.

38. Tanaka S. Emerging anti-osteoclast therapy for rheumatoid arthritis. J Orthop Sci 2018;23:717-21.

39. Mavrogenis AF, Flevas DA, Panagopoulos GN, et al. Rapid destructive arthritis of the hip revisited. Eur J Orthop Surg Traumatol 2015;25:1115-20.

40. Kekatpure AL, Sun JH, Sim GB, et al. Rapidly destructive arthrosis of the shoulder joints: radiographic, magnetic resonance imaging, and histopathologic findings. J Shoulder Elbow Surg 2015;24:922-7.

41. Charrois O, Kahwaji A, Rhami M, et al. Outcome after total hip arthroplasty performed for rapidly progressive hip destruction in French). Rev Chir Orthop Reparatrice Appar Mot 2002,88:236-44.

42. El-Farrash RA, Ali RH, Barakat NM. Post-natal bone physiology. Semin Fetal Neonatal Med 2020;25:101077.

43. Fukui K, Kaneuji A, Fukushima M, et al. Inversion of the acetabular labrum triggers rapidly destructive osteoarthritis of the hip: representative case report and proposed etiology. J Arthroplasty 2014;29:2468-72.

44. Fujita H, Ochi M, Ono M, et al. Glutathione accelerates osteoclast differentiation and inflammatory bone destruction. Free Radic Res 2019;53:226-36.

45. Ono T, Nakashima T. Recent advances in osteoclast biology. Histochem Cell Biol 2018;149:325-41.

46. Chen X, Wang Z, Duan N, et al. Osteoblast-osteoclast interactions. Connect Tissue Res 2018;59:99-107.

47. Abe H, Sakai T, Ando W, et al. Synovial joint fluid cytokine levels in hip disease. Rheumatology (Oxford) 2014;53:165-72. 